\title{
Importância do ambiente de jardim de infância Waldorf no desenvolvimento da coordenação motora de crianças de quatro a seis anos
}

Resumo: Este artigo teve como objetivo investigar a importância que o ambiente de jardim de infância Waldorf tem sobre o desenvolvimento motor de crianças de quatro a seis anos nos dias atuais. Essa pesquisa foi realizada com alunos e professores da educação infantil da escola Cora Coralina, por meio de um trabalho de campo de caráter qualitativo e abordagem exploratória. Observou-se 20 crianças, com foco em seus movimentos corporais, bem como as estruturas que são acessíveis a elas. Aplicou-se entrevista semiestruturada com duas professoras, a fim de apreender a visão e condução pedagógica de uma escola Waldorf acerca da temática. Dentre os fatores analisados, a liberdade de experimentação, o ambiente rico em desafios e o respeito ao ritmo pessoal foram pontos ressaltados. Evidenciou-se que o espaço estudado, assim como a conduta pedagógica Waldorf, ao possibilitar às crianças conhecerem e superarem seus limites dentro de seu tempo, exercem papéis fundamentais para um salutar desenvolvimento motor na contemporaneidade.

Palavras-chave: Pedagogia Waldorf. Ambiente. Desenvolvimento motor. Crianças.

\section{Introdução}

O ambiente de jardim de infância Waldorf apresenta-se na contramão dos avanços tecnológicos da contemporaneidade, ao estimular o brincar fora em contato com a natureza e seus elementos, com atividades coletivas ou individuais, e, portanto, atua de forma diferenciada na coordenação motora das crianças de quatro a seis anos.

Nos últimos 30 anos, o desenvolvimento motor nos primeiros sete anos de vida de um ser humano e o papel do ambiente nesta fase foram temas de muitas pesquisas. Evidenciou-se variações individuais, no aparecimento de novos comportamentos e desempenho motor das crianças, que ultrapassam as explicações genéticas e taxas de maturação. (NAZÁRIO; VIEIRA, 2014)

Segundo Rodrigues e colaboradores (2013) o ambiente social das crianças, bem como suas brincadeiras, modificaram-se muito; houve uma grande redução de brincadeiras tradicionais, que despertam as habilidades motoras amplas e as habilidades motoras fundamentais. Hoje o acesso às mídias e jogos eletrônicos tem chamado a atenção de muitas crianças para atividades
Luisa Coneglian Brandão Universidade do Sul de Santa Catarina - UNISUL luisab_9@hotmail.com

Claudia Jesus Tietsche Reis Universidade do Sul de Santa Catarina - UNISUL

claudia.tietsche@gmail.com 
que exigem muita concentração e pouco movimento físico, pelo menos no que se refere à movimentação motora ampla. (OSANAI; OLIVEIRA, 2014)

O avanço tecnológico, a forma de brincar e o brincar em si, foram sofrendo mudanças significativas e, consequentemente foram se distanciando de brincadeiras coletivas de rua tais como: ciranda cirandinha, pular amarelinha, pular corda, abrindo espaços para brincadeiras cada vez mais voltadas para aparatos tecnológicos como, por exemplo, celulares, tablets, computadores que por sua vez acabaram por fazer com que essas brincadeiras que antes eram comuns, fossem caindo no esquecimento das crianças de hoje. (OSANAI; OLIVEIRA, 2014, p. 125)

A violência ou falta de segurança, e mesmo o grande movimento das cidades, por meio do tráfego intenso e do ritmo acelerado econômico, têm tirado as crianças das ruas e as colocado cada vez mais dentro de suas casas e apartamentos, em contato com aparelhos eletrônicos (RODRIGUES; CARVALHO, 2009).

Para Tieppo (2015) quando se troca jogos com bola reais por vivências virtuais, muito do desenvolvimento motor amplo fica prejudicado. Segundo Queiroz e Pinto (2010) as crianças estão expostas a ambientes com menores possibilidades de exploração e experimentação motora e por consequência estão cada vez mais sedentárias e inseguras. Barros e colaboradores (2003) afirma que para um bom desenvolvimento motor é importante que esse ambiente crie possibilidades de exploração e interações diversas.

Deve-se observar os ambientes a que essa criança pertence para uma melhor e mais profunda compreensão do desenvolvimento motor na infância. (KREBS, 1997) A criança se movimenta de acordo com as condições que há ao seu redor e como consequência de sua experimentação pessoal desenvolverá algumas características mais que outras. (BÉZIERS; PIRET, 1992)

É através da riqueza de experimentações, que as crianças irão construir um sólido e diversificado repertório motor que levarão para a vida e se tornarão capazes de enfrentar os desafios que o cotidiano traz. A qualidade de espaços e materiais, assim como uma situação pedagógica adequada, pode contribuir nesse desenvolvimento. (PALMA; CAMARGO; PONTES, 2012) 
Segundo Haywood e Getchell (2014) o ambiente sociocultural é o impulsionador de nossos comportamentos. Alguns ambientes, tal como a escola de pedagogia Waldorf, reforçam o contato da criança com o meio, através de brincadeiras corporais amplas, ao incentivar uma diversidade de possibilidades e experimentações, que pode atuar em suas habilidades motoras.

Segundo Lanz (2000) o ambiente criado através dos princípios da pedagogia Waldorf, que recebe crianças de quatro a seis anos, é chamado de jardim de infância. Nele, as crianças brincam de forma livre, com pouca interferência dos adultos e com materiais propícios a cada faixa etária. O contato com a natureza, elementos naturais e desafios corporais é fundamental nesse espaço. Estimula-se a autonomia para que as crianças ganhem confiança em seus próprios corpos, desenvolvendo habilidades.

A pedagogia Waldorf ${ }^{1}$ busca respostas às problemáticas fundamentais da sociedade atual, com base nos conhecimentos antropológicos estudados por Rudolf Steiner no início do século XX. Acredita-se que a criança aprende na seriedade do seu brincar, diferente do aprender brincando, pois ela necessita da autoridade para ser livre. A criança antes dos sete anos é puro instinto. (STEINER, 2000)

A criança sadia vive inicialmente em seu mundo, orientada pelos movimentos e por sua vontade, e segue seus instintos, seusimpulsos, suas cobiças e seus desejos. Sem um modelo a imitar, sem orientação, ficaria num nível onde não há liberdade. Se desejarmos que ela tome o caminho rumo a si mesma è̀ liberdade,é necessário que vivencie o mundo como um campo de treino e como um desafio. Sem a ajuda de um educador, a parte espiritual-individual da criança dificilmente encontraria o meio correto de integrar-se à própria corporalidade e à corporalidade do mundo. Tal integração deve se dar de modo que nenhuma dessas duascorporalidades a impeça de seguir o caminho rumo à autonomia, à capacidade de julgamento e, na idade apropriada, à livre escolha. (RICHTER, 2002, p. 25)

Segundo Guttenhofer (2012) a educação da criança não acontece de forma direta, mas somente quando elas podem participar progressivamente do trabalho do adulto. Portanto, em um ambiente ideal, o educador deve se manter ativo, não ensinando diretamente as crianças, mas trabalhando em atividades necessárias à vida nesse ambiente. A criança imita o que vê, quando observa
(1) A primeira escola Waldorf no Brasil surgiu em fevereiro de 1956 em São Paulo e, em função da alta demanda por profissionais qualificados para esta pedagogia, no ano de 1970, nasceu o primeiro Centro de Formação de Professores em pedagogia Waldorf no Brasil. Atualmente, existem quase 100 escolas brasileiras federadas em pedagogia Waldorf, mesmo esta filosofia pedagógica não sendo uma unanimidade, assim como nenhuma outra corrente pedagógica. O livro Clarear - a pedagogia Waldorf em debate, da Ana Lúcia Machado, traz esse contraponto por meio de algumas vivências de crianças e questionamentos dos pais. 
o educador movendo seus braços e pernas no trabalho, sente-se convidada a fazer o mesmo em um processo de autoeducação.

$\mathrm{Na}$ pedagogia Waldorf, trabalho e brincar correm juntos, um inspirando o outro. O currículo se desenvolve baseado nas necessidades dos alunos e não em uma imposição quantitativa de informações. O padrão curricular entre as escolas consiste na forma como os conteúdos são trabalhados artisticamente e sempre pelas vivências. (FRANS; KLINGBORG, 2006)

\footnotetext{
Os movimentos são significativos para as crianças quando correspondem as suas possibilidades e situações de vida [...] Ensinar certos padrões de movimento contraria a natureza do desenvolvimento motor, porque a criança deveria estar pronta para ele, conforme postulam certos tipos de terapia motora. (SHOOREL, 2013, p. 156)
}

Nesse universo da conquista da coordenação motora, o brincar livre das crianças se relaciona diretamente ao desenvolvimento infantil. Steiner (2014) diz que um bom educador é aquele que serve como guia, ao orientar as crianças a criar um ritmo, mas sem nunca interferir de forma bruta no desabrochar delas.

Portanto, o tema que embasa esse artigo surgiu da contextualização do movimento corporal da infância na sociedade, discutindo-se sobre e o que pode proporcionar o ambiente do jardim de infância das escolas Waldorf quanto à movimentação e exploração corporal. Consequentemente, o presente estudo buscou investigar a importância desse ambiente para o desenvolvimento da coordenação motora das crianças de quatro a seis anos.

\section{Materiais e métodos}

Este artigo é resultado de uma pesquisa qualitativa com abordagem exploratória. O estudo qualitativo desenvolve-se numa situação natural, é rico em dados descritivos, tem um plano aberto e flexível e evidencia a realidade de forma complexa e contextualizada. Esse estudo se constitui como um trabalho de campo, que focaliza uma comunidade, utilizando como coleta de dados a observação direta das atividades do grupo e entrevistas com participantes da pesquisa.

A amostra pesquisada foi composta por 20 alunos com idade entre quatro e seis anos, matriculados na mesma sala de jardim 
de infância da Escola Cora Coralina e dois professores atuantes na educação infantil desta mesma instituição.

A etapa de observação do trabalho de campo durou oito encontros, distribuídos em um período de quatro semanas. A pesquisadora permaneceu duas horas a cada visita, observando as crianças no pátio, parte externa do jardim de infância, ambiente mais evidente para a movimentação motora.

Os critérios de inclusão dos alunos para participação no estudo contemplam: a idade entre quatro e seis anos, a matrícula na turma de jardim de infância da Escola Cora Coralina no segundo semestre de 2016 e a autorização documentada por seu responsável legal. Quanto aos professores, o critério foi atuar como docente em uma turma de jardim da Escola Cora Coralina, no mesmo período.

Os critérios excludentes discentes abrangem: a apresentação de deficiência físico-motora ou mental que comprometa o aparelho motor, estar com algum membro quebrado ou engessado, além de desistência por qualquer motivo. Para os professores o motivo de exclusão se restringe à desistência.

Os instrumentos de coleta de dados foram: observação de campo e entrevistas semiestruturadas. A observação proporciona um contato direto do pesquisador com o fenômeno, enquanto a entrevista semiestrutura viabiliza o reconhecimento do comportamento não verbal do participante, ampliando a capacidade de análise.

Durante a observação, identificou-se a forma como as crianças se movimentam, brincam e exploram o presente ambiente. O foco esteve voltado para as estruturas que são acessíveis a elas, bem como quais são as possibilidades de movimentos amplos que essas promovem.

As brincadeiras das crianças foram assistidas com o máximo de neutralidade, a fim de se observar a realidade vivida nesse ambiente. Considerou-se todas as expressões motoras das crianças, as quais foram descritas no diário de campo, avaliando a proximidade do momento como pré-requisito para maior acuidade.

A partir das perguntas abertas da entrevista semiestruturada com as professoras do jardim, buscou-se investigar qual a influência do ambiente e da forma de atuar da pedagogia Waldorf no desenvolvimento motor das crianças na sociedade atual.

A análise foi feita a partir dos dados coletados por meio das anotações no diário de campo e dos áudios referentes às entrevistas respondidas pelas professoras do jardim de infância. Os resultados 
foram discutidos com base nas bibliografias atuais sobre o tema, a fim de encontrar um referencial que possibilitasse comparações e conclusões acerca do desenvolvimento motor.

Como técnica para analisar os dados, utilizou-se a análise de conteúdo, uma ferramenta interpretativa, que apresenta como função básica a observação mais atenta dos significados presentes em um texto. No caso do presente estudo foi analisado tanto o diário de campo, que abarca o conteúdo recolhido com a observação, quanto às transcrições das entrevistas com as professoras.

Para a realização desse estudo, foram respeitadas as recomendações da Resolução no 466/12 do Conselho Nacional de Saúde, por se tratar de uma pesquisa com seres humanos. Foi assegurado aos participantes e seus responsáveis o anonimato e sigilo de suas informações, bem como o direito de desistirem de participar do estudo, se assim desejassem. Os mesmos tiveram como direito assegurado à divulgação dos resultados do estudo, sem exposição de seus nomes ou informações pessoais que causassem algum tipo de constrangimento físico, moral ou psicológico. As informações obtidas através do estudo serão conservadas por um período de cinco anos. Número de aprovação no Comitê de Ética em Pesquisa da Universidade do Sul de Santa Catarina (CEP/UNISUL): 57761916.7.0000.5369.

\section{Resultados e discussão}

A partir da pergunta norteadora do trabalho - qual a importância de um ambiente de jardim de infância Waldorf para o desenvolvimento da coordenação motora de crianças de quatro a seis anos nos dias atuais? - os resultados obtidos por meio das entrevistas e do diário de campo possibilitaram um espaço abrangente de discussão.

No levantamento de dados por intermédio da observação, foram investigados os movimentos e suas frequências, tanto pela mesma criança quanto por diferentes crianças, em cada um dos ambientes destinados ao brincar livre na Escola Cora Coralina. Os dados foram organizados conforme o quadro abaixo.

\section{Quadro postado separadamente.}

Duas das árvores que compunham o ambiente destinado ao brincar externo eram grandes, com troncos largos e muitos 
galhos disponíveis para as crianças subirem. O trepa-trepa, o escorregador e o balanço acoplavam-se nelas, proporcionando às crianças circuitos interligados para terminarem uma atividade já iniciando a próxima.

As crianças tinham livre acesso a diversos objetos de madeira como uma grande carriola, caixotes, caixas, estrado, espadas, além de outros materiais para pneu, panelas e copos; assim como os elementos da própria natureza como pedras, folhas, sementes, terra e areia. Enfim, uma oferta que possibilitava práticas coletivas e individuais diversificadas e criativas, alternando movimentos amplos e sutis.

Ao chegar à fase da maturidade de seu desenvolvimento motor, a criança está apta a desempenhar eficientemente suas expressões mecânicas, de forma coordenada e controlada. Ao observar tais expressões, pode-se classificar, segundo Gallahue e Ozmun (2005), em três categorias: movimentos estabilizadores, que são aqueles que em algum nível exigem equilíbrio; os locomotores, que são aqueles que se relacionam ao movimento de deslocamento e os manipulativos, que podem ser os rudimentares, ligados a, por exemplo, um arremesso de bola, apanhar, chutar e derrubar um objeto e os refinados, que se referem a movimentos de músculos menores da mão e do punho.

Ao relacionar os movimentos observados em campo com a classificação descrita, identificou-se que as três categorias foram contempladas, destacando-se mais os movimentos locomotores, que permearam todos os ambientes. O brincar fora proposto pela prática pedagógica da escola observada possibilitou deslocamentos variados das crianças, desde corridas em desnível, como representante do deslocamento horizontal, até saltos e escaladas de alturas variadas, como representantes do deslocamento vertical; ambos que exigiam presença, destreza e superação desafiadora.

Depois dos locomotores, os movimentos mais observados foram os estabilizadores, evidenciados, principalmente, nos ambientes com árvores, trepa-trepa, escorregador e balanço, e no de brincadeiras sem objetos. A habilidade com que as crianças subiam nas árvores e delas passavam para algum outro brinquedo, solicitava equilíbrio, coragem e percepção corporal de forma natural, na seriedade de suas brincadeiras.

Por último, os movimentos manipulativos, presentes mais claramente nos ambientes com corda e de brincadeiras com ou- 
tros objetos, por meio de corridas e caminhadas com objetos de tamanhos e formas variadas, como a carriola cheia de crianças dentro, caixotes de madeira e troncos robustos; permitindo o exercício da força e prontidão.

Os pesquisadores Gallahue e Ozmun (2005) afirmam que para chegar ao estágio mais desenvolvido do movimento, ou maturidade, é necessária a oportunidade de praticar, bem como o encorajamento e um ambiente fértil. Nessas situações adequadas, as crianças são capazes de desempenhar a maioria dos movimentos fundamentais por volta dos seis anos.

Existem testes específicos para mensurar o nível do desenvolvimento motor, como o teste de avaliação motora grossa (TDMG2), validado no Brasil por Valentini e colaboradores (2008) que mensura de forma precisa o desempenho motor. O fato desse teste não ter sido aplicado nesse estudo, restringiu a comparação dos resultados observados a trabalhos de revisão bibliográfica. Portanto, esse estudo teve seu foco voltado para a observação das crianças a partir dos conceitos antroposóficos da pedagogia Waldorf, norteadores desse ambiente e prática.

As crianças carregaram objetos leves e pesados - grandes e pequenos; equilibraram-se em árvores, em cordas, no alto e no baixo; caminharam e correram sozinhas ou coletivamente, em níveis diversos de chão irregular. Permitiram usar ao máximo seus corpos de forma ativa e viva, desafiando-se e aprimorando sua destreza diariamente.

As professoras entrevistadas, reportadas neste artigo com nomes fictícios, contextualizaram a pedagogia Waldorfe as crianças presentes na Escola Cora Coralina, quanto ao comportamento e hábitos nos desafios contemporâneos. Afirmaram sobre o papel fundamental desta pedagogia nos dias de hoje, ao contribuir com o desenvolvimento motor e, consequentemente, com a conquista da liberdade.

Segundo a professora Violeta, durante o primeiro setênio, as crianças estão completando o desenvolvimento de seu corpo físico, e para isso o movimento é essencial. Elas são incentivadas a subirem e explorarem o ambiente e seus corpos com confiança e segurança, sem serem reprimidas, desencorajadas ou amedrontadas. A criança tem liberdade para descobrir os limites e perigos da vida com pouca ou nenhuma interferência dos adultos. 
Eles vão ter confiança e eles vão explorar o espaço e nessa exploração eles vão descobrir as suas capacidades. [...] Cada vez mais eles vão conseguir subir mais alto; eles vão conseguir dar um pulinho mais quando estão pulando corda. Eles vão, enfim, descobrindo o potencial desse corpinho deles. (VIOLETA)

A criança é movida, segundo Lanz (2000), por irresistíveis impulsos motores descontrolados, que podem ser chamados de vontade. É, então, a partir dessa vontade que a criança vai ao mundo e descobre o prazer de correr, de subir em árvores, de escorregar. Descobre o prazer do corpo e seu movimento. A partir dos quatro anos, os membros da criança crescem longitudinalmente, ela sofre um alongamento de seu corpo e ganha uma maior agilidade, essas modificações coincidem com o despertar da vontade dirigida. (LIEVEGOED, 1994)

Para Lanz (2000) toda a vontade conduz a criança ao movimento. Não é saudável inibir brutalmente essa vontade em potencial, mas aos poucos trazer uma regularidade e ritmo a ela, que tende a ficar caótica se não orientada. Esse tipo de prática docente, com a atenção voltada para a vontade das crianças, pôde ser observada no trabalho de campo e confirmada pela fala das professoras. "Ela não é conduzida então, é a vontade, algo que vem de dentro dela [...] é um desenvolvimento motor de acordo com a necessidade que ela tem, se o ambiente está propício a isso." (LIRIO).

Como fator impulsionador da vontade que se transforma em movimento, destacou-se o convívio das crianças umas com as outras, por meio de seus jogos, brincadeiras e desafios. Esse contato e envolvimento direcionaram à experimentação e expansão de seus repertórios motores; é na relação que elas conhecem e ultrapassam seus próprios limites.

Steiner (2014) afirma que o melhor brinquedo é aquele que possibilita à criança exteriorizar aquilo que já existe nela, algo não pronto e acabado, permitindo à criança criar. No ambiente de jardim, há à disposição uma variedade de objetos pesados, grandes e de certa forma inacabados, que permitem às crianças criarem de formas diferentes jogos e brincadeiras, ampliando a forma de interação dos mesmos, como conta a professora Lírio:

Tábuas, troncos, essas coisas, e tudo pesado, de madeira[...]eles fazem alavanca, eles fazem gangorra, equilibram um monte de coisas, os caixotes que caem no chão, sabe[...]. Então o jardim tem 
que ter esses desafios, tem que ter coisas que tragam isso. Tem que ter corda, pular corda, tem que ter isso, tem que ter brinquedos que façam com que ela desenvolva o equilíbrio, como: corda bamba, aquele banquinho que a gente tem que é uma madeira bem fininha, com um pé só. A árvore que ela sobe e pode se tornar tudo, porque é equilíbrio, é força [...].

Steiner (2014) salienta que para um completo e saudável desenvolvimento na primeira infância é necessário que o educador aja como um guia, mas não exerça coação. É necessário respeitar o que a natureza humana quer, deixá-la livre e apenas exercer o papel de guia auxiliar e protetor. Lírio ilustra na prática o que Steiner idealizou nesta pedagogia: "é essa liberdade no pátio que faz com que ela ponha pra fora ou vá ao encontro de, procure, inconscientemente, os desafios que ela precisa desenvolver".

Na visão das professoras, o próprio brincar livre, que parte da vontade e interesse da criança, é que promove o desenvolvimento motor dessas, apenas quando é percebido que uma criança está muito atrás em seu desenvolvimento, ela é convidada a realizar brincadeiras específicas para fortalecer e desenvolver o que necessita no momento.

Na formação do colegiado dos professores, a temática do brincar livre é condição para o trabalho pedagógico Waldorf. A seriedade do brincar das crianças é respeitada em todo o seu desenvolvimento. A partir da observação de campo evidenciou-se a liberdade promovida pelas professoras que não interviam nesse brincar, nem nas escaladas em grandes alturas, ou no manuseio de objetos bem pesados. O objetivo da liberdade tinha uma relação direta com o incentivo à autonomia.

Segundo Lírio, os professores observam e avaliam as crianças o tempo todo. Se uma criança não pula corda, não faz isso, não faz aquilo, ainda assim ela é convidada a participar. Ao invés de chamá-la individualmente para uma brincadeira, usa-se sempre o verbo no plural, para coletivamente e, portanto, naturalmente, incluí-la.

Às vezes você pode até conduzir pra uma coisa que você sabe que a criança precise como pular corda. Você precisa que a criança ganhe uma separação dos membros inferiores e superiores, $e$ quando eles estão pulando corda, quando eles têm essa liberdade, que eles começam a chegar nessa prontidão deles[...]. Então você chama pra uma coisa assim, mas normalmente eles brincam, 
porque brincar é o que eles sabem fazer se a gente deixar, eles não precisam que a gente diga nada. Eles sobem, eles descem, eles inventam as brincadeiras todas e pra cada uma dessas coisas eles estão fazendo experiências de equilíbrio, as experiências sociais; quem brinca, quem não brinca[...] se tem alguma criança que tá um pouquinho mais pra trás em alguma questão aí sim a gente pode pedir que façam algumas coisas, como caminhar em cima de uma coisa em alturinha pra ele ganhar um pouco mais de equilíbrio, ou criança que precisa girar um pouquinho mais, aí a gente vai vendo quais são as necessidades e as capacidades que eles tem que desenvolver. (VIOLETA)

O desenvolvimento do aparelho motor, na visão antroposófica, instiga outras esferas do desenvolvimento humano. A importância do desenvolvimento motor saudável vai muito além das qualidades meramente físicas: musculares ou esqueléticas. Segundo Lanz (2000), há uma forte ligação entre o andar ereto, o pensar e a fala, características desenvolvidas nessa fase. Um andar não desenvolvido corretamente pode influir em defeitos de fala ou raciocínio. Em contrapartida, exercícios motores podem corrigir dificuldades na fala ou no pensar.

Steiner (2014) diz que o falar é um resultado de nossa orientação no espaço. É quando a mão deixa de ser um aparelho locomotor (engatinhar/segurar para se manter em pé) e passa a atuar em gestos, forma-se no cérebro o centro da fala. (LIEVEGOED, 1994) A brincadeira auxilia o desenvolvimento cognitivo e cinético, além de externalizar problemas e emoções. "A brincadeira une cabeça, mãos e coração". (CLOUDER; NICOL, 2009, p. 6)

Também dentro da sala de aula de uma escola Waldorf, são estimulados movimentos corporais, enquanto as crianças cantam e falam versos em roda, brincando, imitando os movimentos da professora.

A gente rola, a gente finge de cachorrinho, porque tem isso, a criança tem que ter engatinhado, tem que ter rastejado ao longo do seu desenvolvimento assim e ai a gente proporciona momentos em que ela vai rastejar, vai virar cachorrinho, vai andar que nem um lagarto, tudo coisa que o bebê faz, que tem criança que tem um déficit nesses movimentos[...] E o momento da roda é o momento de você fazer esses movimentos, com todos, mas que acaba atingindo os que precisam. (LIRIO) 
Na visão antroposófica, o fator mais importante nos primeiros sete anos e que guia a criança e seu desenvolvimento é o processo da imitação. A imitação, segundo Schoorel (2013) significa ser movido, é a capacidade de se deixar guiar. A professora Violeta compartilhou que por meio da imitação, a criança começa a explorar o mundo, tornando necessário aos adultos - educadores e pais - a consciência de serem pessoas imitáveis em cada uma de suas ações.

A pedagogia Waldorf é considerada mais que um método de ensino, mas uma educação terapêutica, pois considera o homem em sua pluralidade e assim propõe atitudes e formas de conduzi-lo para seu melhor e mais harmonioso desenvolvimento.

\section{No jardim de infância Waldorfo que realmente a gente tem que ter é um conhecimento antropológico do desenvolvimento das crian- ças, do ser humano, pra gente entender qual é o alimento correto pra cada fase dele e permitir que essas crianças se desenvolvam por elas mesmas num ambiente tranquilo e seguro. (VIOLETA)}

Ou seja, o tempo e o ritmo da criança devem ser respeitados, cada fase de desenvolvimento pede uma condução diferente, não é prudente acelerar ou pular etapas no desenvolvimento infantil. "Qualquer ensino de abstração, como o da leitura, contraria a natureza própria da criança, perturbando seu desenvolvimento e produzindo nela males que se manifestam posteriormente, sob forma psicológica ou mesmo fisiológica". (LANZ, 2000 p. 213)

Outro fator abordado nas entrevistas foi a mudança observada nas crianças, nas últimas décadas, a alteração da movimentação corporal, do ritmo em casa. "Corporalmente elas tinham, elas eram mais exigidas corporalmente, com certeza, porque assim a bicicleta estava mais presente. Hoje eu tenho aluno que não sabe andar de bicicleta e tem quase sete anos" (LIRIO).

Elas estão muito mais despertas na cabeça do que no corpo. Então eles não conseguem ainda chegar no domínio de algumas coisas que pra aquela idade já deveriam ter atingido, mas ao mesmo tempo eles estão com coisas, falando de coisas o tempo inteiro muito ligados [...] eles são mais estabanados muitas vezes [...] Eles tem uma moleira, uma preguiça [...] a gente tá vendo cada vez mais criança de primeiro setênio com preguiça [...] uma certa hesitação eu vejo, tem crianças que tão menos confiantes em fazer as coisas[...] isso é uma falta de empoderamento desse corpo (VIOLETA). 
Lievegoed (1994) já observou as mesmas modificações citadas pelas professoras e suas consequências nas crianças, como a modificação do ambiente nas cidades, a pressa e ritmo acelerado, a falta de tempo dedicada à infância e a exigência de conhecimentos intelectuais cada vez mais cedo tanto em casa quanto nas escolas, observando uma metamorfose intelectual prematura nas crianças, que muitas vezes gera prejuízos em seu desenvolvimento corporal.

Outra pesquisa recente confirma a observação das professoras, para Queiroz e Pinto (2010) percebe-se que as crianças estão cada vez mais sedentárias e inseguras e com menores possibilidades no desenvolvimento de sua motricidade, pois estão cada vez mais vivenciando experiências que visem o intelecto em detrimento das atividades motoras.

E a professora Violeta ainda completa:

Eu acho que a grande influência negativa que nós tivemos foi a televisão, virou babá da maioria das crianças [...] botar na frente do computador, botar na frente da televisão é a mesma coisa: você tá tirando a criança do brincar e tá dando pra ela um alimento que ela não tá pronta pra receber então vai dar uma indigestão.

Segundo Lanz (2000) os eletrônicos restringem nossa individualidade, por conter suas possibilidades programadas e rígidas. Um exemplo são os jogos eletrônicos em que as crianças são presas pela excitação competitiva e têm sua consciência alienada. Além de desconexão de seus sentimentos e corpo, que são forçados a seguir o padrão imposto no jogo, criam novas conexões cerebrais, artificiais e mecânicas. Na primeira infância o jogo eletrônico substitui e pode retardar e até inibir os movimentos da criança em uma época crucial em que todo seu foco está no andar, pensar e falar.

Os eletrônicos, incluindo televisão, computador e celular, têm um perfil irresistível e extremamente atrativo para as crianças. Trazem toda a informação já pronta e rápida, não permitindo espaço para a imaginação. A criança fica em comportamento passivo, que tende a gerar um padrão hiperativo e ansioso após seu uso e até uma incapacidade de concentração e inatividade (imaginativa ou física) e distúrbios do sono. (LANZ, 2000)

A professora Violeta dialoga com as afirmações de Lanz (2000) ao constatar que muitas crianças não conseguem descrever fatos com coerência, de forma presente, sem pressa. Apresentam 
abstinência de paciência, querem sempre uma novidade, outra novidade, dificultando a concentração e assimilação das vivências.

Por isso no ambiente de jardim, promove-se que as crianças fiquem longos períodos imersos em uma única brincadeira, em cima das árvores, criando sozinhas, a partir de seus impulsos e vontade; proporcionando formas de se envolverem, desafiarem-se e desbravarem seus limites. Foi observado crianças que ficaram muitos minutos imersos, por exemplo, observando uma formiga no chão, agachados, sem desviar sua atenção. Ao parafrasear a professora Violeta, constata-se que no jardim de infância Waldorf, seu diferencial acontece no contemplar a natureza, tornando-a mais significativa às crianças. Ensina-se a reverência a tudo que tem vida, desde a formiga até uma frondosa árvore; portanto, ressignifica a importância da vitalidade dos grandes movimentos.

Sugere-se, em futuros estudos, que se expandam as possibilidades e locais de observação, além de que se investigue a rotina comportamental que essas crianças têm fora do ambiente escolar, em seus lares, para complementação da discussão e análise através da comparação.

\section{Considerações finais}

Contextualizado o que foi observado no diário de campo, apreendido através das entrevistas e o que a literatura discute hoje sobre o desenvolvimento motor, é possível observar o ambiente de jardim de infância Waldorf como um ambiente propício e benéfico para o desabrochar da criança em seus aspectos motores essenciais da primeira infância.

$\mathrm{Na}$ visão antroposófica, no período dos primeiros sete anos de vida, as crianças percebem o mundo experimentando-o. Precisam expandir seus movimentos na interação com a natureza, fato pouco explorado na sociedade tecnologicamente urbana, em que as crianças passam cada vez mais tempo envolvidas com os meios eletrônicos e dentro de casa.

Essa mudança comportamental torna ainda mais evidente a necessidade de se balancear essa relação, expondo as crianças a ambientes que possibilitem explorar e interagir com o mundo real e natural. Assim, ao buscar o desenvolvimento saudável e equilibrado do ser humano, o ambiente Waldorf surge não apenas como um ambiente benéfico, mas, também, como um ambiente 
essencial para contrabalancear os excessivos estímulos eletrônicos aos quais as crianças estão expostas na atualidade.

A pedagogia Waldorf, segundo Ribeiro (2009), pode ser entendida como atemporal, pois se baseia nas "dimensões essenciais do ser humano": querer, sentir e pensar. Em que o pensar se relaciona ao passado, o sentir ao presente e o querer ao futuro. Este trabalho teve seu enfoque no movimento, na vontade, no querer, portanto, direcionou-se ao futuro. O jardim de infância Waldorf pode ser entendido como um ambiente no qual a criança tem espaço para conhecer e superar seus limites dentro de seu tempo.

A observação de campo permitiu experimentar além da teoria conceitual, ou seja, a liberdade e a autonomia postas em prática, pilares defendidos por essa linha pedagógica. Observar as crianças soltas, confiantes, conhecendo e desvendando seus limites, trouxe grandes reflexões acerca da capacidade que existe na criança e que muitas vezes não é expressa por falta de espaço e oportunidade.

Movimentos desafiadores, como alcançar o topo de uma árvore muito alta, que muitas vezes poderiam ser julgados como perigosos e reprimidos por pais e educadores, são promovidos dentro desse brincar livre Waldorf. A confiança dirigida às crianças por meio dos professores foi um fator destacado nesse trabalho. Quando há confiança e espaço para as crianças, por si mesmas, movimentarem-se, possibilita-se a construção de sua autonomia e seu desenvolvimento acontece, em todos os níveis.

O respeito ao desenvolvimento físico e motor das crianças estrutura o ser humano para além de suas habilidades motoras. Esse ser estará apto para lidar com os desafios que a vida trará, equilibrando-se tal como nas cordas do jardim, desafiando-se, tal como subir no galho mais alto da árvore.

\section{Importance of the Waldorf kindergarten environment on the development of motor coordination of children from four to six years}

\footnotetext{
Abstract: This article aimed to investigate the importance that the Waldorf kindergarten environment has on the motor development of children from four to six years of age in the present days. This research was carried out with students and teachers of the childhood education of the school Cora Coralina, through a field work of qualitative character and exploratory approach. Twenty children were observed, focusing on their body movements, as well as the structures that are accessible to them. A semi-structured interview was
} 
applied with two teachers to apprehend the vision and pedagogical conduction of a Waldorf school about the theme. Among the analyzed factors, the freedom of experimentation, the environment rich in challenges and the respect to the personal rhythm were highlighted points. It was evidenced that the space studied, as well as the Waldorf pedagogical conduct, by allowing children to know and overcome their limits within their time, exert fundamental roles for a salutary motor development in the contemporaneity.

Keywords: Waldorf pedagogy. Environment. Motor development. Children.

\section{Referências}

BARROS, Karla Mônica F. T. de et al. Do environmental influences alter motor abilities acquisition? A comparison among children from day-care centers and private schools. Arquivos de Neuro-Psiquiatria, São Paulo, v. 61, n. 2A, p. 170-175, jun. 2003. Disponível em:

$<$ http://www.scielo.br/scielo.php?script $=$ sci_arttext\& pid $=$ S0004282X2003000200002 >. Acesso em: 22 abr. 2016.

BEZIERS, Marie-Madaleine; PIRET, Suzane. A coordenação motora: aspecto mecânico da organização psicomotora do homem. São Paulo: Summus, 1992.

CLOUDER, Cristopher; NICOL, Janni. Brincadeiras criativas para seu fitho: uma forma lúdica para aumentar a concentração e melhorar o desenvolvimento dos pequenos. São Paulo: Publifolha, 2009.

FRANS, Carlgren; KLINGBORG, Arne. Educação para a liberdade: a pedagogia de Rudolf Steiner. Tradução Edith Kunze e Kurt Kunze. São Paulo: Escola Waldorf Rudolf Steiner, 2006.

GALLAHUE, David; OZMUN, John. Compreendendo o desenvolvimento motor: bebês, crianças, adolescentes e adultos.São Paulo:Phorte, 2005.

GUTENHOFER, Peter. Salvando a infância. Boletim Sociedade Antroposófica, São Paulo, ano XVIII, p. 12-15, ago./set./out., 2012.

HAYWOOD, Kathleen M. GETCHELL, Nancy. Desenvolvimento motor ao longo da vida. Porto Alegre: Artmed, 2014.

KREBS, Ruy. A teoria dos sistemas ecológicos: um paradigma para a educação infantil. Santa Maria: Editora da Universidade Federal de Santa Maria; 1997.

LANZ, Rudolf. A pedagogia Waldorf: caminho para um ensino mais humano. São Paulo: Antroposófica, 2000.

LIEVEGOED, Bernard. Desvendando o crescimento: as fases evolutivas da infância e da adolescência. São Paulo: Antroposófica, 1994.

NAZÁRIO, Patrik Felipe; VIEIRA, José Luiz Lopes. Sport context and the motor development of children. Revista Brasileira de Cineantropometria \& Desempenho Humano, Florianópolis, v. 16, n. 1, p. 86-95, 2014. Disponível em: <http://www.scielo.br/scielo. php?script $=$ sci_arttextE pid $=$ S1980-00372014000100086 > . Acesso em: 22 abr. 2016. 
OSANAI, Lidiane Shizue; OLIVEIRA, Marta Regina Furlan.

As crianças e suas brincadeiras: um olhar na contemporaneidade.

Londrina: Universidade Estadual de Londrina, 2014. Disponível em: <http://www.uel.br/eventos/jornadadidatica/pages/arquivos/

III\%20Jornada\%20de\%20Didatica\%20-\%20Desafios\%20para\%20a\%20

Docencia\%20e\%20II\%20Seminario\%20de\%20Pesquisa\%20do\%20

CEMAD/AS\%20CRIANCAS\%20E\%20SUAS\%20BRINCADEIRAS\%20

UM\%20OLHAR\%20NA.pdf>. Acesso em: 20 maio 2016.

PALMA, Míriam Stock; CAMARGO, Vinícius Arnaboldide; PONTES, Maicon Felipe Pereira. Efeitos da atividade física sistemática sobre o desempenho motor de crianças pré-escolares. Revista da Educação Física/UEM, Maringá, v. 23, n. 3, p. 421-429, set. 2012. Disponível em: <http://www.scielo.br/scielo.php?pid=S1983$30832012000300010 \&$ script $=$ sci_abstract\&tlng $=$ pt $>$.

Acesso em: 22 abr. 2016.

QUEIROZ, Liliane Tobelem da Silva; PINTO, Ricardo Figueiredo.

A criança: fatores que influenciam seu desenvolvimento motor. Revista Digital, Buenos Aires, ano 14, n. 143. Abril de 2010. Disponível em:

<http://www.efdeportes.com/efd143/a-crianca-seu-desenvolvimentomotor.htm > Acesso em: 25 maio 2016.

RICHTER, Tobias. Objetivo pedagógico e método de ensino de uma escola Waldorf. São Paulo: Federação das Escolas Waldorf do Brasil, 2002.

RODRIGUES, Luzia Maria; CARVALHO, Carlos Roberto. A criança e o brincar. Rio de Janeiro, 2009. Disponível em: < http://www.ufrrj.br/ graduacao/prodocencia/publicacoes/desafios-cotidianos/arquivos/ integra/integra_RODRIGUES.pdf>. Acesso em: 27 maio 2016.

SCHOOREL, Edmond. Os primeiros sete anos: fisiologia da infância. São Paulo: Antroposófica, 2013.

STEINER, Rudolf. A filosofia da liberdade. Tradução Karin Glass.

São Paulo: Antroposófica, 2000.

STEINER, Rudolf. Andar, falar, pensar: a atividade lúdica. São Paulo: Antroposófica, 2014.

TIEPPO, Carla. Tecnologia e desenvolvimento motor das crianças. Revista Neuroeducação, Londrina, set., 2015. Disponível em: < http:// revistaneuroeducacao.com.br/tecnologia-e-desenvolvimento-motor-dascriancas/ > . Acesso em: abr. 2016.

VALENTINI, Nadia Cristina et al. Teste de Desenvolvimento Motor Grosso: validade e consistência interna para uma população gaúcha. Revista Brasileira de Cineantropometria e Desempenho Humano, Florianópolis, v. 10, n.4, p. 399-404, 2008. Acesso em: 28 maio 2016.

Submetido em: 10 de junho de 2017 | Aceito em: 29 de outubro de 2017 
